\title{
EVALUATION OF RATIONAL USE OF ANTIBIOTIC DRUGS IN SURGERY DEPARTMENT AT A TERTIARY CARE HOSPITAL
}

\author{
SREEJA NYAYAKAR*, MANDARA MS, HEMALATHA M, LALLAWMAWMI, MOHAMMED SALAHUDDIN, \\ FATEMEH HASANI
}

Department of Pharmacy Practice, Hillside College of Pharmacy and Research Centre, Bengaluru, Karnataka, India. Email: sreejanyayakar999@gmail.com

Received: 13 November 2020, Revised and Accepted: 21 January 2021

ABSTRACT

Objective: Antibiotics are the only drug where use in one patient can impact the effectiveness in another, so antibiotic misuse adversely impacts the patients and society. Improving antibiotic use improves patient outcomes and saves money. Antibiotic resistance has been identified as a major threat by the WHO due to the lack of development of new antibiotics and the increasing infections caused by multidrug resistance pathogens became untreatable.

Methods: A prospective observational study was conducted for a period of 6 months. Data were collected from prescriptions and inpatient record files at the surgery department of the tertiary care hospital. Patients above age of 18 years of either gender whose prescription containing the antibiotics and patients who are willing to participate in the study were included in the study. Microsoft Excel was used for recording and analyzing the data of recruited subjects.

Results: During our study period, we have collected 100 cases as per inclusion criteria, in total collected 100 cases, $52 \%$ are male and $48 \%$ are female. The mean age and standard deviation of the study population were found to be $46.61 \pm 16.12$. The most commonly prescribed classification before and after the surgery is cephalosporin's that is 57\%. Results show that in pre-surgery, almost 93\% of prescriptions have chosen the drugs as per ASHP guidelines, whereas in post-surgery, $95 \%$ of drugs have selected the drug as per ASHP guidelines.

Conclusion: Our study has observed that some of the prescriptions are irrationally prescribed so the pharmacist has to take the responsibility to improve the awareness regarding rational prescribing of antibiotics. The national wide monitoring of antibiotics use, national schemes to obtain rational use of antibiotics, reassessing the prescriptions, education to practitioners, and surveys on antibiotics should be implemented.

Keywords: Antibiotics, Rational use, WHO, ASHP guidelines, Monitoring.

(C) 2021 The Authors. Published by Innovare Academic Sciences Pvt Ltd. This is an open access article under the CC BY license (http://creativecommons.org/ licenses/by/4.0/) DOI: http://dx.doi.org/10.22159/ajpcr.2021v14i3.40239. Journal homepage: https://innovareacademics.in/journals/index.php/ajpcr

\section{INTRODUCTION}

Antibiotic was first used in 1942 by Selman Waksman and his collaborators in journal articles. The term antibiotics are applied to any medication that kills bacteria or inhibits their growth, regardless of whether that medication is produced by a microorganism or not [1]. The purpose of this study is to highlight the rational use of antibiotics to achieve an optimal outcome of the infection with minimization of the toxicity, reduction of costs, and also the limitation of microbial resistance [2]. Irrational use of medicines is a global problem. It has been estimated that less than half of all medicines are prescribed, dispensed, or sold inappropriately. Less than half of all patients take their medicines as prescribed or dispensed. Irrational use of medicines can harm patients in terms of poor patient outcome, unnecessary ADR, and wastage of resources, often out-of-pocket payments by patients. Irrational use of antibiotics is particularly serious because it is contributing to the AMR that is increasing rapidly worldwide and is causing significant morbidity and mortality and billions of dollars worth of extra health-care costs annually [3].

The development of resistance to antibiotics in bacteria often develops as a result of unnecessary and inappropriate use of antibiotics. Today, on the one hand, trying to develop new drugs, on the other hand, there are difficulties in treatment as a result of the development of resistance to these drugs rapidly. The development of resistance to antibiotics is a major health problem all over the world [4].

The concept of pre-operative antibiotic prophylaxis was introduced by Strachan in 1977 [5]. Surgical antibiotic prophylaxis (SAP) is the course of antibiotics that are initiated before the starting of the operative procedure. Reduce the post-operative surgical site infections, guidelines indicate that appropriate SAP is an effective measure for preventing SSI [6]. SAP decreases the incidence of SSI after the surgery. SSI increases the length of the hospital stay [7]. Antibiotics are the most commonly prescribed, sold, and used drugs globally [8]. Utilization of drug based on operational research is valuable tools for the provision and maintenance of adequate pharmaceutical services to the majority of population [9]. There is a serious threat to human health and welfare and undermines national economies worldwide, thus antimicrobials should not be used to treat non-bacterial infections and this notion derives from a fundamental perception of the rational use of medicines that these should be used appropriately, in accordance with clinical needs [10]. Several issues need to be addressed in the context of the pharmacist's role in combating antimicrobial resistance. Our study aims to evaluate the rational use of antibiotic drugs using standard guidelines in the surgery department of tertiary care hospitals. The main objectives of our study include to study demographic characteristics of patients who are prescribed antibiotics in the surgery department, to evaluate the prescription pattern of drugs as per the WHO indications, to analyze the prescription pattern according to essential drug list, and to evaluate the rational use of antibiotics characteristics.

\section{METHODS}

Study design

This was a prospective observational study. 
Study population

Inclusion criteria

The following criteria were included in the study:

- Inpatients were prescribed antibiotics

- Patients above 18 years of age of either gender

- Patients who are willing to participate.

\section{Exclusion criteria}

The following criteria were excluded from the study:

- Surgery patients where antibiotics are not prescribed

- Patient with psychiatric disease

- The patient who is not willing to sign to inform consent form

- Lactating and pregnant women.

\section{Data instrument}

Data would be collected from prescription and inpatient record files of the subject included in the study at the surgery department.

\section{Sample size}

Estimated sample size is 100 patients.

\section{Statistical analysis}

Microsoft Excel was used for recording and analyzing the data of recruited subjects. Descriptive statistical analyses were used to calculate the average and standard deviation.

\section{RESULTS AND DISCUSSION}

During our study period, we have collected 100 cases as per inclusion criteria, total collected 100 cases $52 \%$ are male and $48 \%$ are females.
Fig. 1 describes the gender and age distribution. Males are more when compared to females this result was supported by other studies conducted by Shukry [8] and Sumon [9]. The maximum number of patients was found between the ages of 31-40. The maximum age of the study population is 87 and the minimum age of the study sample is 15 . The mean age and standard deviation of the study population were found to be $46.61 \pm 16.12$.

In the sample size, of 100 most common diagnoses in the surgery ward include appendicitis, fissures, cellulitis, diabetic foot, pancreatitis, paraumbilical hernia, and cholecystitis. In our study, we have classified the surgeries performed using the national elective surgery urgency categorization and results Table 1 shows that $42 \%$ of patients have undergone general surgery, $21 \%$ of patients have undergone gynecology surgery, $20 \%$ of patients have undergone neurosurgery, $7 \%$ of patients have undergone vascular surgery, $6 \%$ of patients have undergone otolaryngology surgery, and remaining patients have undergone surgeries such as urological, orthopedic and plastic, and reconstructive surgery. When it comes to the duration of surgery, most of the surgeries are performed with a period of 1-2 h. The length of the hospital stay varies with the type of surgery from our results we can say that most patients who have undergone surgery have stayed for 6-10 days in the hospital and these results were supported by the study conducted by Alamkere [6]. Our study results regarding wound classification shows that nearly $32 \%$ of them are under the category of clean contaminated, $31 \%$ of them are under the category of dirty, $25 \%$ of them are under the category of contaminated, and $12 \%$ are clean, this shows that most of them are not clean and these results were supported by the study conducted by Sumon [9].

Fig. 2 describes the common classification of drugs that were used before and after surgery for prophylaxis. Results show that the most

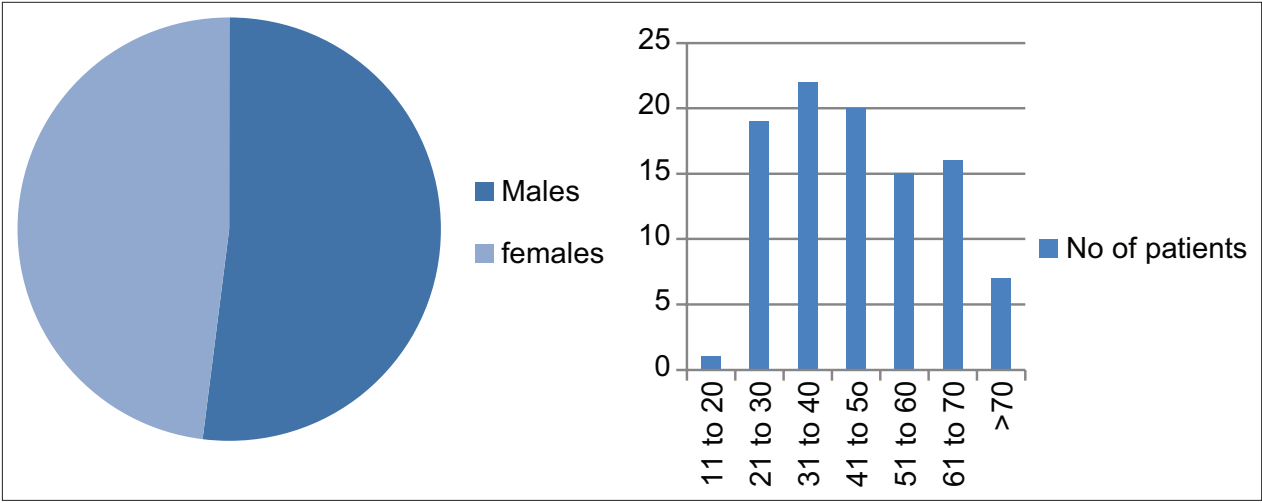

Fig. 1: Gender and age distribution

Table 1: Categorization based on different variables

\begin{tabular}{|c|c|c|c|}
\hline Variable & Category & No. of patients & Percentage \\
\hline \multirow[t]{7}{*}{ Type of surgery } & General surgery & 45 & 45 \\
\hline & Gynecology surgery & 17 & 17 \\
\hline & Neurosurgery & 22 & 22 \\
\hline & Orthopedic surgery & 1 & 1 \\
\hline & Otolaryngology surgery & 6 & 6 \\
\hline & Plastic and reconstructive surgery & 2 & 2 \\
\hline & Urological surgery & 1 & 1 \\
\hline \multirow[t]{3}{*}{ Duration of surgery } & Less than $1 \mathrm{~h}$ & 32 & 32 \\
\hline & $1-2 \mathrm{~h}$ & 63 & 63 \\
\hline & More than $2 \mathrm{~h}$ & 05 & 5 \\
\hline \multirow[t]{3}{*}{ Length of hospital stay } & $1-5$ & 40 & 40 \\
\hline & $6-10$ & 57 & 57 \\
\hline & $11-15$ & 03 & 3 \\
\hline \multirow[t]{3}{*}{ Wound classification } & Clean & 12 & 12 \\
\hline & Clean contaminated & 32 & 32 \\
\hline & Dirty & 31 & 31 \\
\hline
\end{tabular}


commonly prescribed classification before and after the surgery is cephalosporin's that is $57 \%$ and these results were supported by Shukry [8], Sumon [9], and Alamkere [6], next to cephalosporin's commonly used antibiotic classification is nitroimidazoles that is $16 \%$, in which these are commonly used classification in both pre- and postsurgery antibiotics. The other antibiotic classifications used in pre- and post-surgery are aminoglycosides, penicillins, lincomycin, and others. When compared to the pre-surgery, the choice of aminoglycosides in post-surgery prophylaxis is more.

Table 2 gives information regarding the commonly prescribed antibiotic drug during pre- and post-surgery for prophylaxis. Results show that taxim is the most commonly prescribed antibiotic under the cephalosporin classification for patients at the pre-operative stage and metrogyl is the most commonly prescribed antibiotic under the classification of nitroimidazoles for patients at the post-operative stage.

Fig. 3 gives information about the number of antibiotics used for prophylaxis during pre- and post-surgery. This shows that most

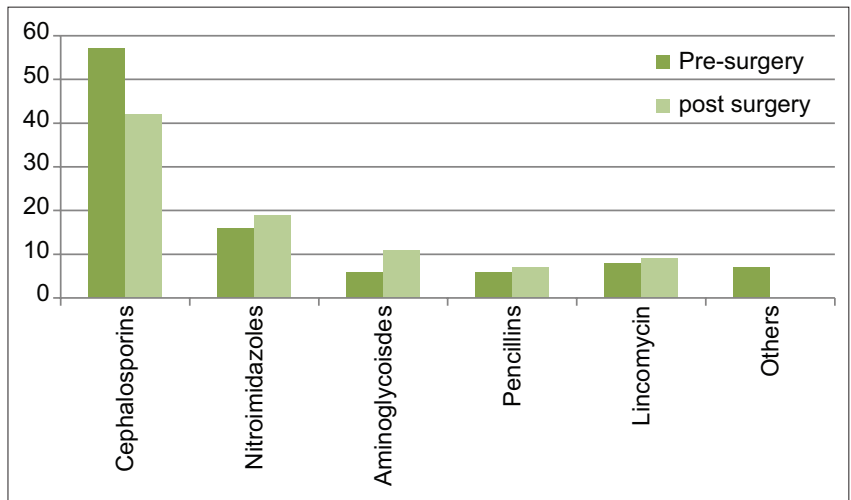

Fig. 2: Commonly prescribed antibiotics classification

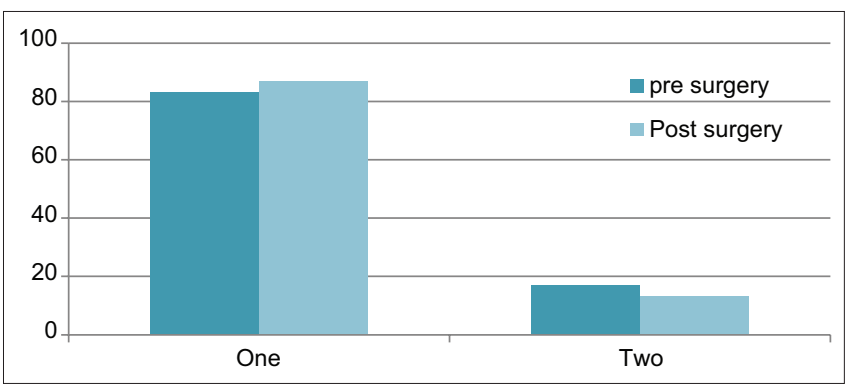

Fig. 3: Number of prophylactic antibiotics used

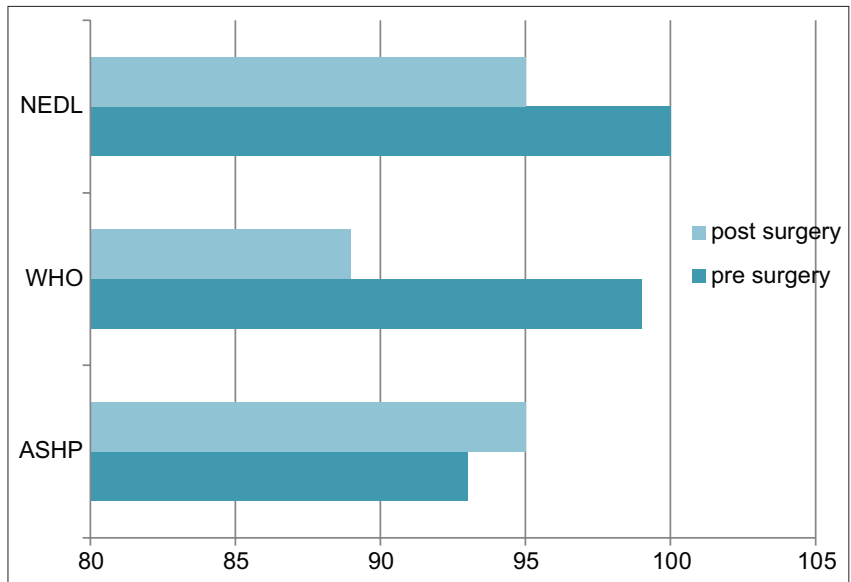

Fig. 4: Evaluation of prescription using standard guidelines physicians prefer to prescribe monotherapy for the prophylaxis and these results were supported by the study conducted by Sumon [9].

Table 2: Commonly prescribed antibiotics

\begin{tabular}{|c|c|c|c|c|}
\hline \multirow[t]{2}{*}{ Classification } & \multicolumn{2}{|c|}{ Pre-operative } & \multicolumn{2}{|c|}{ Post-operative } \\
\hline & $\begin{array}{l}\text { No. of } \\
\text { patients }\end{array}$ & $\%$ & $\begin{array}{l}\text { No. of } \\
\text { patients }\end{array}$ & $\%$ \\
\hline Taxim & 48 & 48 & 11 & 11 \\
\hline Cefotaxime & 3 & 3 & 0 & 0 \\
\hline Taxim+Metrogyl & 4 & 4 & 0 & 0 \\
\hline Clindamycin & 1 & 1 & 10 & 10 \\
\hline Ceftriaxone & 1 & 1 & 5 & 5 \\
\hline Vancomycin & 6 & 6 & 0 & 0 \\
\hline Taxim, metrogyl & 5 & 5 & 2 & 2 \\
\hline Clindamycin, metrogyl & 1 & 1 & 0 & 0 \\
\hline Augmentin & 6 & 6 & 4 & 4 \\
\hline Metrogyl & 10 & 10 & 15 & 15 \\
\hline Piperacillin & 1 & 1 & 2 & 2 \\
\hline Linezolid & 1 & 1 & 2 & 2 \\
\hline Augmentin, clindamycin & 2 & 2 & 0 & 0 \\
\hline Ciplox & 1 & 1 & 5 & 5 \\
\hline Amoxiclav & 1 & 1 & 3 & 3 \\
\hline Ampicillin, dicloxacillin & 1 & 1 & 0 & 0 \\
\hline Doxycycline & 1 & 1 & 0 & 0 \\
\hline Amoxicillin, penicillin & 2 & 2 & 0 & 0 \\
\hline Cefoxitin & 1 & 1 & 0 & 0 \\
\hline Taxim 0 & 1 & 1 & 5 & 5 \\
\hline Claritin, taxim & 2 & 2 & 0 & 0 \\
\hline Orinda, Ciplox & 1 & 1 & 0 & 0 \\
\hline Rifampicin & 0 & 0 & 1 & 1 \\
\hline Amikacin & 0 & 0 & 2 & 2 \\
\hline Linosept & 0 & 0 & 2 & 2 \\
\hline Monocef & 0 & 0 & 2 & 2 \\
\hline Orni-O & 0 & 0 & 6 & 6 \\
\hline Meropenem & 0 & 0 & 2 & 2 \\
\hline Amikacin & 0 & 0 & 1 & 1 \\
\hline Amikacin+Lined & 0 & 0 & 1 & 1 \\
\hline Metrogyl+Amoxiclav & 0 & 0 & 2 & 2 \\
\hline Amoxiclav & 0 & 0 & 1 & 1 \\
\hline Gramocef & 0 & 0 & 3 & 3 \\
\hline Nucetax & 0 & 0 & 2 & 2 \\
\hline Clarivit & 0 & 0 & 1 & 1 \\
\hline Cefixime & 0 & 0 & 1 & 1 \\
\hline
\end{tabular}

Table 3: Evaluating the prescription using the WHO prescribing indicators

\begin{tabular}{lll}
\hline S. No. & WHO prescribing indicates & Value (Aug) \\
\hline 1. & $\begin{array}{l}\text { The average number of drugs } \\
\text { per encounter }\end{array}$ & 9.2 \\
2. & $\begin{array}{l}\text { Percentage of drug prescribed by } \\
\text { generic name }\end{array}$ & 68 \\
3. & $\begin{array}{l}\text { Percentage of encounter with an } \\
\text { antibiotic prescribed }\end{array}$ & 100 \\
4. & $\begin{array}{l}\text { Percentage of encounter with an } \\
\text { Injection prescribed }\end{array}$ & 100 \\
5. & $\begin{array}{l}\text { Percentage of drug prescribed } \\
\text { from essential drug or formulary }\end{array}$ & 88 \\
\hline
\end{tabular}

Table 4: Antibiotic selections based on the class of wound

\begin{tabular}{lll}
\hline Class of wound & $\begin{array}{l}\text { Most commonly } \\
\text { prescribed antibiotic }\end{array}$ & Percentage \\
\hline Clean & Cefixime & 46.1 \\
Clean contaminated & Cefixime & 48.4 \\
Contaminated & Cefixime & 84.6 \\
Dirty & Cefixime & 62.5 \\
\hline
\end{tabular}


Table 5: Descriptive statistics

\begin{tabular}{|c|c|c|c|c|c|c|c|c|}
\hline \multirow[t]{2}{*}{ Variables } & \multicolumn{8}{|c|}{ Type of surgery } \\
\hline & $\begin{array}{l}\text { General } \\
\text { surgery } \\
\mathrm{n}=44\end{array}$ & $\begin{array}{l}\text { Gynecology } \\
\text { surgery } \\
\mathbf{n}=17\end{array}$ & $\begin{array}{l}\text { Neurosurgery } \\
n=22\end{array}$ & $\begin{array}{l}\text { Orthopedic } \\
\text { surgery } \\
n=1\end{array}$ & $\begin{array}{l}\text { Otolaryngology } \\
\text { surgery } \\
n=6\end{array}$ & $\begin{array}{l}\text { Plastic and } \\
\text { reconstructive } \\
\text { surgery } \\
\mathbf{n}=2\end{array}$ & $\begin{array}{l}\text { Urological } \\
\text { surgery } \\
\mathbf{n}=\mathbf{1}\end{array}$ & $\begin{array}{l}\text { Vascular } \\
\text { surgery } \\
n=6\end{array}$ \\
\hline \multicolumn{9}{|l|}{ Gender } \\
\hline Males & 17 & 8 & 16 & 1 & 3 & 1 & 1 & 4 \\
\hline \multicolumn{9}{|l|}{ Age distribution } \\
\hline $11-20$ & 1 & 0 & 0 & 0 & 0 & 0 & 0 & 0 \\
\hline $21-30$ & 11 & 4 & 1 & 0 & 3 & 0 & 0 & 0 \\
\hline $31-40$ & 11 & 3 & 4 & 1 & 2 & 0 & 0 & 0 \\
\hline $41-50$ & 7 & 3 & 9 & 0 & 0 & 1 & 1 & 0 \\
\hline $51-60$ & 5 & 1 & 5 & 0 & 1 & 0 & 0 & 2 \\
\hline $61-70$ & 9 & 4 & 1 & 0 & 0 & 1 & 0 & 1 \\
\hline$>70$ & 0 & 2 & 2 & 0 & 0 & 0 & 0 & 3 \\
\hline Clean & 10 & 0 & 0 & 0 & 2 & 0 & 0 & 0 \\
\hline $\begin{array}{l}\text { Clean } \\
\text { contaminated }\end{array}$ & 15 & 10 & 0 & 0 & 0 & 1 & 0 & 1 \\
\hline Contaminated & 12 & 4 & 7 & 1 & 4 & 1 & 0 & 0 \\
\hline Dirty & 7 & 3 & 15 & 0 & 0 & 0 & 1 & 5 \\
\hline \multicolumn{9}{|l|}{$\begin{array}{l}\text { Length of } \\
\text { hospital stay }\end{array}$} \\
\hline $1-5$ & 19 & 9 & 6 & 0 & 3 & 1 & 1 & 1 \\
\hline $6-10$ & 24 & 8 & 15 & 1 & 3 & 1 & 0 & 4 \\
\hline $11-15$ & 1 & 0 & 1 & 0 & 0 & 0 & 0 & 1 \\
\hline
\end{tabular}

Table 3 evaluates the prescribing pattern of medicines using the WHO prescribing indicators, this shows that the average number is $9.2,68 \%$ of drugs prescribed by generic name, and almost $100 \%$ of prescriptions are encountered with antibiotic and have at least one injection in their prescription, and $88 \%$ of drugs were prescribed from essential drug list or formulary.

Table 4 shows the information regarding the choice of antibiotic based on wound classification, it shows that cefixime is the commonly used drug for clean, clean contaminated, contaminated, dirty wounds but the results obtained by the other author show that different types of antibiotics used based on the different types of wound classification [9].

Table 5 shows the information regarding the effect of various variables such as age, gender, Wound classification, and length of hospital stay on type of surgery. Results show that females are more prone to general surgery when compared to males, males are more prone to neurosurgery when compared to females. The patients between the age group of 21 and 40 have undergone majorly general surgery and the patients above the age of 40 have undergone majorly neurosurgery. When it comes to wound classification, most of the general surgeries are under the category of clean contaminated and most of the neurosurgeries come under the category of wound classification dirty. The length of hospital stay is more for general, neuro, and gynecology surgeries whereas the length of the hospital is less for orthopedic surgeries.

Fig. 4 shows the information regarding how many prescriptions are following the standard guidelines and results show that in pre-surgery, almost $93 \%$ of prescriptions have chosen the drugs as per ASHP guidelines, whereas in post-surgery, $95 \%$ of drugs have selected the drug as per ASHP guidelines. This shows that most of the prescriptions will follow the guidelines of ASHP.

\section{CONCLUSION}

Prophylactic use of antibiotics reduced the incidence of post-operative wound infection, appropriate choice of antibiotics can reduce the hospital stay and development of antibiotic resistance. Our study has observed that some of the prescriptions are irrationally prescribed so the pharmacist has to take the responsibility to improve the awareness regarding rational prescribing of antibiotics and also pharmacist has to take responsibility in monitoring and enforcement of antibiotics policy in the hospital. The national wide monitoring of antibiotics use, national schemes to obtain rational use of antibiotics, reassessing the prescriptions, education to practitioners, and surveys on antibiotics should be implemented.

\section{Limitations}

The study was conducted from a single hospital and it may not be representative of the pattern across India. The study was out for a short duration of time, if the duration was more the effectiveness would be more.

\section{ACKNOWLEDGMENT}

The authors would like to thank the management and staff of Hillside College of Pharmacy and Research Center, Bengaluru, and Dr. Satish and Dr. Manoj Karthik for their constant support and guidance.

\section{AUTHORS' CONTRIBUTIONS}

All the authors have contributed equally.

\section{CONFLICTS OF INTEREST}

Declared none.

\section{REFERENCES}

1. Pawan $\mathrm{S}$, Navneet V, Prevesh K, Priyanka N. Review on the potential of antibiotics. J Drug Deliv Ther 2018;8:35-40.

2. Kourkouta L, Kotsiftpoulos CH, Papageorgiou M, Iliadis CH, Monios A. The rational use of antibiotics medicine. J Healthc Commun 2017;2:1-4.

3. Kathleen AH. Promoting the rational use of antibiotics. Reg Health Forum 2011;15:122-30.

4. Salih C, Ali PD. Antibiotics and the mechanism of resistance to Antibiotics. Med J Islam World Acad Sci 2013;21:138-42.

5. Prashant D, Prakash G, Subodh U. A comparative study for the role of preoperative antibiotics prophylaxis in the prevention of surgical site 
infections. IOSR J Pharm 2014;13:27-31.

6. Alemkere G. Antibiotic usage in surgical prophylaxis: A prospective observational study in the surgical ward of Nekemte referral hospital. PLoS One 2018;13:e203523.

7. SIGN Antibiotic Prophylaxis in Surgery. A National Clinical Guideline; 2008. p. 1-71. Available from: http://www.just.edu.jo/ar/dic/guidelines.

8. Shukry Z, Chathurangani H, Hana M. Assessing knowledge, perception and attitudes about antibiotics among final year pharmacy undergraduates in Sri Lanka. Int J Pharm Pharm Sci 2017;9:234-9.

9. Sumon KD, Tripti RP, Monalisa M, Ambia K, Rafiqul I, Ali A, et al. Patterns of prescription and antibiotic use among outpatients in a tertiary care teaching hospital of Bangladesh. Int J Pharm Pharm Sci 2016;8:60-3

10. Suman L, Vijay K, Vineeta S, Sanjay S. Prescribing pattern of antibiotics among outdoor patient in medicine department of tertiary care hospital in Northern India. Int J Pharm Pharm Sci 2020;12:43-6. 